\title{
Effect of an environmental barrier to physical activity on commuter stair use
}

\author{
Johan Faskunger, Eric Poortvliet, Kamilla Nylund and Jenny Rossen
}

Unit for Preventive Nutrition, Novum, Department of Biosciences, Karolinska Institutet and Stockholm County

Council, Huddinge, Sweden

\begin{abstract}
Background: Despite several health benefits of physical activity, few adults appear to be regularly active. The constructed environment is increasingly being recognized as a main barrier to physical activity, and is therefore important to target to encourage people to adopt a more active lifestyle.

Objective: To investigate stairwell and escalator use in a train station in a situation in which the setting was modified during the intervention (one or two ascending escalators) to increase understanding of how physical activity could be promoted in such environment.

Design: One hour observation of commuters $(n=1614)$ in a situation with one $(n=854)$ or two $(n=760)$ ascending escalators.

Results: With only one ascending escalator, $35.2 \%$ of the population decided to climb the stairwell. With two ascending escalators, stairwell use dropped to $18.2 \%(p=0.000)$. The drop in stairwell use between the two conditions was thus nearly $50 \%$ and the use of escalators increased by $27 \%$.

Conclusions: This brief intervention provided an indication that a modification to the constructed environment influenced the decision to climb the stairwell. However, more experimental research is needed to investigate how people can be encouraged to take the stairs in similar and other settings.
\end{abstract}

Keywords: community, environment, physical activity, stair use.

Received: 26 November 2002; Accepted: 20 January 2003

\section{Introduction}

Regular physical activity confers several physical, mental and functional health benefits, and reduces the burden of disease (1). Despite the substantial health benefits, reliable data are starting to become available indicating that people in general are relatively sedentary (2). Owing to the high magnitude of the health risk, and the apparently large proportion of the adult population living a largely sedentary lifestyle, the promotion of regular physical activity has become one of the most important tasks for public health.

Researchers are increasingly turning their attention to ecological models targeting the environment to promote public health and reduce the burden of lifestyle-related disease $(3,4)$. The constructed environment is increasingly being recognized as being a main barrier to, and asserting a negative influence on, a physical active lifestyle in modern Western society (3). Most of us live in environments believed to be strongly conducive to sedentary behaviour.

However, despite the high potential, research and interventions targeting the environment to promote physical activity are scarce.
Volitional behavioural choices do not occur in a vacuum but are the product of reciprocal interactions between attitudes, norms, behaviour and the surrounding environment (5). The way in which environment influences physical activity behaviour may be conceptualized as ranging from situations of almost complete restriction of behavioural choice or barriers to physical activity through different levels of situations of semi-restricted behavioural choice to situations of optimal incentives for physical activity or barriers to physical inactivity.

Previous studies in the area have investigated the effects of prompts or cues in the form of informational or educational posters and stair-banners promoting stair use in situations of semi-restricted behavioural choice (i.e. both stairs and escalator available), with short-term positive effects on physical activity behaviour (e.g. (6-11)). Indeed, a recent systematic review (12) provided evidence that interventions using point-of-decision prompts to encourage stair use were likely to be highly cost-effective across diverse settings and population groups, although the effects showed a downward trend when the signs were removed. 
The present study investigated stair and escalator use at a commuter train station in Stockholm, Sweden, in a situation in which the environment was modified in favour of either escalator use (two escalators ascending) or stair use (only one escalator ascending). It is argued that this is of importance to investigate the behavioural effect following more substantial modifications to the environment.

\section{Methods}

\section{Behavioural setting}

The commuter train station is situated in a suburb of Stockholm near a university and university hospital. To exit the train station one must either ascend an escalator or climb 51 steps in an adjacent stairwell. The escalators can be reversed and used either for ascent or descent depending on commuter demand.

\section{Procedure}

Stair use was observed between 08.00 and $09.00 \mathrm{~h}$ during rush hour. During the intervention, commuters from four trains experienced the situation favouring stair use (only one ascending escalator), while passengers from five trains experienced the situation favouring escalator use (two ascending escalators).

\section{Measures}

Observations were made at the top of the stairwell near the exit from the station. In the situation favouring stairwell use, two researchers observed the ascending escalator while the other two observed the stairwell. In the situation favouring escalator use, two researchers observed the busier escalator, the third researcher observed the other ascending escalator, while the remaining researcher observed the stairwell.

\section{Results}

In total, 1614 passengers were included in the study. Of the 1614 passengers, 1174 used the ascending escalator(s) while 440 climbed the stairwell. In the situation favouring stair use, $35.4 \%(n=302 / 854)$ decided to climb the stairwell, while $64.6 \%$ decided to opt for the ascending escalator. However, when the other escalator was reversed, favouring escalator use, only $18.2 \%(p=0.000)$ decided to climb the stairwell, while $81.8 \%$ used one of the two ascending escalators. The drop in stairwell use between the two conditions was nearly $50 \%$ and the use of escalators increased by $27 \%$ (Fig. 1).

However, as observed during the intervention, the experiment worked best when a large crowd arrived at the station at the same time, making access to the escalator more difficult. With a smaller group of people, access to the escalator was easier, and fewer people, irrespective of the condition, decided to take the stairwell. To investigate the specific effect of the experiment on commuters' behaviour in a crowded environment, a second analysis investigated trains arriving with more than 150 passengers at a time (at $08.15,08.30,08.45$ and $09.00 \mathrm{~h}$; mean $n$ per train $=$ 291).

In this condition, with one ascending escalator, the percentage of people taking the stairwell reached $38.7 \%(n=237 / 612)$. With two ascending escalators, the percentage of people climbing the stairwell decreased to $22.5 \%(n=124 / 552)$ (Fig. 2).

Furthermore, when stair use by passengers arriving on the three least crowded trains $(08.05,08.35$ and $08.54 \mathrm{~h}$; mean $n$ per train $=69$ ) was investigated in the situation favouring using the escalators (i.e. two ascending escalators), a dramatic drop in use of the stairwell was evident. Only 6.7\% $(n=14 / 208)$ used the stairwell.

\section{Discussion}

This brief study provides an indication that physical activity behaviour could be modified by direct changes to the constructed environment. Thus, in situations in which larger groups of people approach the escalators, by making access to the escalator more difficult, one could potentially have a large, significant impact on the number of people deciding to take the stairwell. Conversely, in situations with no cueing, and the sedentary options readily available, extremely few individuals appear to opt for the stairs. By varying the accessibility to the escalators,

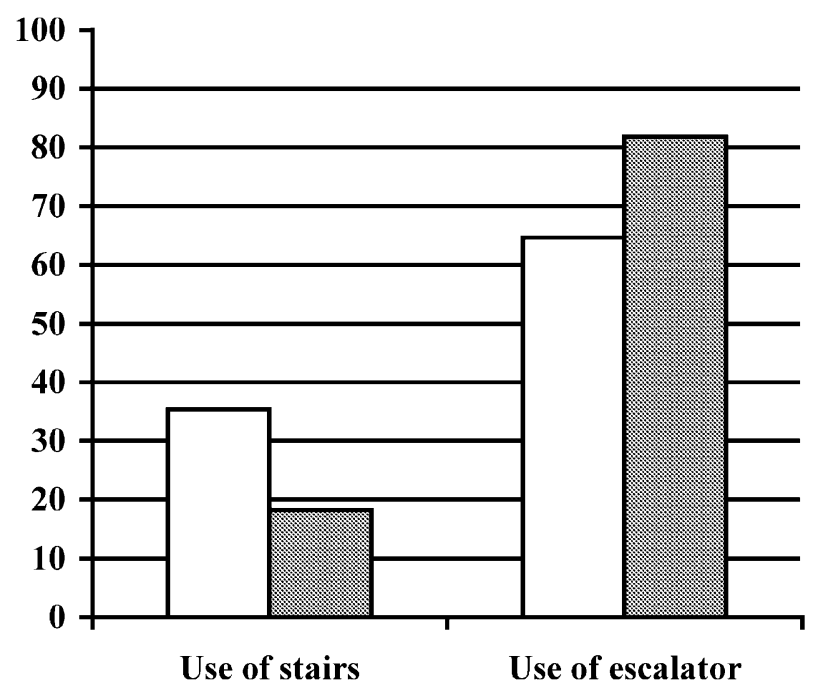

Fig. 1. Percentage of commuters taking the escalator(s) or stairwell in the presence of one ( $\square$ ) or two ( $\square$ ) ascending escalators. 


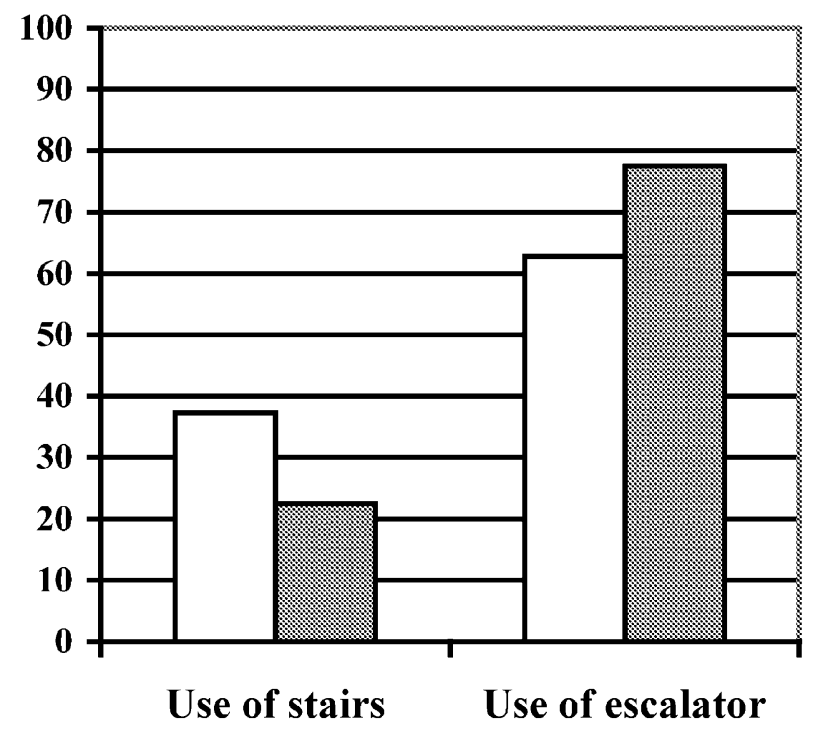

Fig. 2. Percentage of commuters taking the escalator(s) or stairwell in the presence of one $(\square)$ or two $(\boldsymbol{\square})$ ascending escalators in a crowded situation (mean $n$ per train $=291$ ).

and depending on the number of passengers arriving on the same train, the percentage of commuters climbing the stairwell ranged from a nadir of $6.7 \%$ (few passengers, two ascending escalators) to a peak of $38.7 \%$ (many passengers, one ascending escalator).

It should be noted, however, that some people taking the escalator decided to walk up it, thus being physically active as well. In addition, objective data-collection methods are preferable for this type of environmental intervention (13), e.g. to detect differences between people taking the stairwell and the escalator. No check for gender differences was possible, owing to the data-collection method used. Another limitation was the inability to investigate the passengers' motives for taking the stairwell, something that will be investigated in upcoming interventions. Finally, the setting used in this study (e.g. rush hour, two reversible escalators) is likely to differ from other common 'escalatorrich' settings, limiting the ability to generalize. These limitations should be noted when interpreting the findings of this study.

A main message of this study is that much more could, and should, be done to promote lifestylebased health-enhancing physical activity by encouraging people to climb stairs. For this purpose, more research is urgently needed to investigate similar settings with different methodologies and longer time-frames. Considering the strong evidence for the high cost-effectiveness of interventions promoting stair use (12), it seems safe to suggest that more cues and prompts (e.g. posters persuading people to take the stairs for health reasons) should be available in escalator-rich environments. In line with the arguments made by Faskunger and Hemmingsson (14), given the available evidence, it is highly surprising to see the lack of reminders and prompts in society to encourage people to be physically active as part of daily life.

\section{References}

1. US Department of Health and Human Services. Physical activity and health: a report of the Surgeons General. Atlanta, GA: US Department of Health and Human Services, Centers for Disease Control and Prevention, National Center for Chronic Disease Prevention and Health Promotion; 1996.

2. Sjöström M, Yngve A, Ekelund U, et al. Physical activity in groups of Swedish adults: are the recommendations feasible? Scand J Nutr 2002; 46: 123-30.

3. Sallis J, Owen N. Physical activity and behavioral medicine. Thousand Oaks, CA: Sage 1999.

4. Green LW, Kreuter MW. Health promotion planning: an educational and environmental approach. Mountain View, CA: Mayfield 1991.

5. Bandura A. Self-efficacy: the exercise of control. New York: Freeman 1997.

6. Andersen RE, Franckowiak SC, Snyder J, et al. Can inexpensive signs encourage the use of stairs? Results from a community intervention. Ann Intern Med 1998; 129: 363-9.

7. Blamey A, Mutrie N, Aitchison T. Health promotion by encouraged use of stairs. Br Med J 1995; 311: 289-90.

8. Brownell KD, Stunkard AJ, Albaum JM. Evaluation and modification of exercise patterns in the natural environment. Am J Psychiatry 1980; 137: 1540-5.

9. Kerr J, Eves F, Carroll D. Posters can prompt less active people to use the stairs. J Epidemiol Community Health 2000; 54: 942-3.

10. Kerr J, Eves F, Carroll D. Encouraging stair use: stair-riser banners are better than posters. Am J Public Health 2001; 9: 1192-3.

11. Russell W, Dzewaltowski D, Ryan G. The effectiveness of a point-of-decision prompt in deterring sedentary behavior. Am J Health Promotion 1999; 13: 257-9.

12. Kahn EB, Ramsey LT, Brownson RC, et al. The effectiveness of interventions to increase physical activity: a systematic review. Am J Prev Med 2002; 22: 73-108.

13. Sallis J, Bauman A, Pratt M. Environmental and policy interventions to promote physical activity. Am J Prev Med 1998; 15: 379-97.

14. Faskunger J, Hemmingsson E. Addressing overnutrition and physical inactivity - past imperfect, future tense. Scand J Nutr 2002; 46: 100-1.

\footnotetext{
J. Faskunger

Unit for Preventive Nutrition, Novum

Department of Biosciences

SE-I4I 57 Huddinge, Sweden

E-mail: johan.faskunger@prevnut.ki.se
} 